\title{
Principais dificuldades vivenciadas por primíparas no cuidado ao recém-nascido
}

\author{
Main difficulties experienced by primiparies in caring for the newborn
}

Principales dificultades que experimentan los principales en el cuidado del recién nacido

Deyce Danyelle Lopes Silva ${ }^{1 *}$, Edildete Sene Pacheco ${ }^{1}$, Vanessa Rodrigues da Silva², Camila Sabrina de Oliveira Lima ${ }^{3}$, Érica Fernanda Sousa Lima ${ }^{3}$, Vanessa Santos Carvalho ${ }^{1}$ Myslânia de Lima Ribeiro ${ }^{4}$, Sayane Daniela Santos Lima ${ }^{5}$, Carolina Bezerra Valadares ${ }^{2}$, Agna Roberta Rodrigues de Sousa ${ }^{4}$

\section{RESUMO}

Objetivo: Identificar as principais dúvidas e dificuldades vividas pelas puérperas primíparas em relação ao recém-nascido. Métodos: Trata-se de uma pesquisa de campo, descritiva e exploratória de abordagem quanti-qualitativa, realizada no domicílio de 22 primíparas atendidas pelas Estratégia de Saúde da Família (ESF) de um município do interior do estado do Piauí, sendo executada durante o mês de julho de 2016. Resultados: Durante as entrevistas, as participantes foram questionadas quanto às suas dúvidas ou dificuldades enfrentadas para a realização do cuidado ao recém-nascido. A análise das falas obtidas demonstrou que a dificuldade prevalente foi a amamentação, seguida de engasgo e regurgitação; banho e higiene; choro; vacinas e suas reações adversas. Conclusão: As puérperas, embora tenham sido informadas e orientadas quanto aos cuidados com o recém-nascido, apresentaram dúvidas e dificuldades para realizarem tal prática por diversos motivos, sendo a primiparidade o principal deles e revelando aos profissionais de saúde as necessidades no enfrentamento da maternidade.

Palavras-chave: Recém-nascido, Período pós-parto, Serviços de saúde da criança.

\begin{abstract}
Objective: To identify the main doubts and difficulties experienced by primiparous mothers in relation to the newborn. Methods: This is a field research, descriptive and exploratory with a quantitative and qualitative approach, carried out at the home of 22 primiparous women assisted by the Family Health Strategy (FHS) of a municipality in the interior of the state of Piauí, being carried out during the July 2016. Results: During the interviews, the participants were asked about their doubts or difficulties faced in providing care to the newborn. The analysis of the statements obtained showed that the prevalent difficulty was breastfeeding, followed by choking and regurgitation; bath and hygiene; cry; vaccines and their adverse reactions. Conclusion: The puerperal women, although they were informed and oriented about the care of the newborn, presented doubts and difficulties to carry out this practice for several reasons, being primiparity the main one and revealing to health professionals the needs in facing the disease. maternity.
\end{abstract}

Keywords: Newborn, Postpartum period, Child health services.

\footnotetext{
1 Universidade Estadual do Piauí (UESPI), Floriano - PI. *E-mail: deycelopes@gmail.com

2 Universidade Federal do Piauí (UFPI), Teresina - PI.

3 Universidade Federal do Piauí (UFPI), Picos - PI.

${ }^{4}$ Faculdade de Ensino Superior de Floriano (FAESF), Floriano - PI.

${ }^{5}$ Universidade Federal do Piauí (UFPI), Floriano - PI.
} 


\section{RESUMEN}

Objetivo: Identificar las principales dudas y dificultades que experimentan las madres primíparas en relación con el recién nacido. Métodos: Se trata de una investigación de campo, descriptiva y exploratoria con enfoque cuantitativo y cualitativo, realizada en el domicilio de 22 primíparas atendidas por la Estrategia de Salud de la Familia (ESF) de un municipio del interior del estado de Piauí, que se realiza durante el Julio de 2016. Resultados: Durante las entrevistas, se preguntó a los participantes sobre sus dudas o dificultades enfrentadas en la atención al recién nacido. El análisis de las declaraciones obtenidas mostró que la dificultad predominante fue la lactancia materna, seguida de asfixia y regurgitación; baño e higiene; llorar; vacunas y sus reacciones adversas. Conclusión: Las puérperas, a pesar de estar informadas y orientadas sobre el cuidado del recién nacido, presentaron dudas y dificultades para realizar esta práctica por varios motivos, siendo la primiparidad la principal y revelando a los profesionales de la salud las necesidades para afrontar la maternidad.

Palabras clave: Recién nacido, Período posparto, Servicios de salud del niño.

\section{INTRODUÇÃO}

O nascimento do primeiro filho inaugura uma série de transformações, tanto na vida da puérpera como também de seus familiares. O período puerperal é uma fase de adaptações físicas e emocionais em que a mulher aprende a lidar com novas emoções, dificuldades e responsabilidades desconhecidas, gerando sentimentos dúbios e contraditórios (ALMEIDA IS, et al., 2010).

Ao exercer a maternidade pela primeira vez, é comum à mulher demonstrar ansiedade, insegurança, inexperiência, falta de habilidade e receio ao enfrentar essa realidade sem nenhuma experiência prévia. Estes sentimentos ambivalentes são preponderantes na mulher primípara e estão intrinsecamente relacionados à sua realidade socioeconômica e cultural, podendo interferir, inclusive na relação com o bebê (ALMEIDA IS, et al., 2010).

A maternidade pode desencadear uma série de mudanças na vida da mulher, que vão além dos aspectos físicos e emocionais, atingindo também o cotidiano familiar e social. Esse período é caracterizado por insegurança, anseios, medo e inexperiência quanto aos cuidados consigo e com o recém-nascido (COSTA PF e BRITO RS, 2016).

Nesse sentido, pode haver nesse período maior requisição de apoio social. O apoio social apresenta-se como uma ferramenta de suporte psicológico para as mães durante o puerpério, visto que a possibilidade da mãe contar com indivíduos que a auxiliem com as novas demandas, principalmente em momentos de dificuldades e situações estressantes, contribui para facilitar a maternidade, promovendo o desenvolvimento de um apego seguro do binômio mãe e filho (RAPOPORT A e PICCININI CA, 2011; CARDOSO ACA e VIVIAN AG, 2018).

Conhecer as dúvidas, percepções e necessidades das mães primíparas atendidas nos serviços de saúde pública, revelam aos profissionais de saúde as necessidades no enfrentamento da maternidade. Receber informações e orientações necessárias durante o pré-natal ajuda na preparação das gestantes, contribuindo para que as mesmas vivenciem a maternidade com mais tranquilidade, visto que a falta de informações pode gerar preocupações excessivas e expectativas frustradas (SOUZA ZNR, et al., 2011).

Diante de certas dúvidas e dificuldades geradas pela gestação é necessário que os profissionais estejam atentos aos sinais mais evidentes que fujam da adaptação esperada da gestação e puerpério. Portanto, é fundamental o compromisso com a assistência e o alinhamento com os conhecimentos técnico-científicos de todos os profissionais envolvidos no cuidado, seja no pré-natal, alojamento conjunto, na alta hospitalar, visita domiciliar e nas consultas de puericultura (BRASIL, 2012).

A partir das reflexões aqui expostas, o presente trabalho tem por objetivo identificar as principais dúvidas e dificuldades vividas pelas puérperas primíparas em relação ao recém-nascido. 


\section{MÉTODOS}

Trata-se de uma pesquisa de campo, descritiva e exploratória de abordagem quanti-qualitativa. A pesquisa foi realizada no domicílio de 22 primíparas atendidas pelas Estratégia de Saúde da Família (ESF) de um município localizado no sudoeste do Estado do Piauí e executada durante o mês de julho de 2016. As participantes da pesquisa foram localizadas a partir de prontuários de três Unidades Básicas de Saúde (UBS), a escolha de tais UBS justifica-se por serem de fácil acesso por parte das pesquisadoras. Para compor a amostra foi solicitado o auxílio dos Agentes Comunitários de Saúde com o propósito de descobrir a quantidade de primigestas que realizaram pré-natal nas unidades selecionadas e com parto previsto para o período da coleta de dados.

Foram considerados critérios de inclusão: puérperas primíparas, independentemente do tipo de parto, cadastradas nas UBS em estudo, que aceitaram participar voluntariamente da pesquisa. Já os critérios de exclusão: multíparas (mulher que teve mais de um filho) e participantes que durante a execução da pesquisa se recusaram a responder algum questionamento. As informações foram coletadas por meio de entrevistas semiestruturadas, contendo questionamentos elaborados pelas próprias pesquisadoras. As respostas foram transcritas na íntegra e analisadas de acordo com o conteúdo, em três fases: pré-análise, exploração e tratamento do material, posteriormente, realizou-se a inferência e interpretação dos resultados à luz da literatura correspondente (BARDIN L, 2011).

As participantes foram esclarecidas sobre a pesquisa, onde houve a concessão de um tempo adequado para que as convidadas refletissem sobre sua permissão ou não. Logo após os esclarecimentos, as mesmas assinaram o TCLE ou o Termo de Assentimento (para as menores de 18 anos), assegurando que os dados poderiam ser coletados com segurança. O mesmo foi emitido em duas vias, disponibilizando assim, uma para a participante.

Em consonância com as diretrizes e normas da pesquisa com seres humanos, a elaboração do projeto bem como toda sua execução foi pautada nos princípios éticos e orientações da Resolução do Conselho Nacional de Saúde (CNS) № 466/2012, além disso foi submetida ao Comitê de Ética e Pesquisa (CEP) da Universidade Estadual do Piauí (UESPI), onde foi apreciado e aprovado com o número do parecer 1.554.612/2016 (BRASIL, 2012).

\section{RESULTADOS E DISCUSSÃO}

A população em estudo foi constituída por uma amostra de 22 puérperas primíparas sendo a maioria com faixa etária de 20 a 30 anos (50\%), ensino fundamental completo (45,5\%), em um relacionamento estável, que compreende casadas e as que convivem com o companheiro $(59,1 \%)$, estudantes $(45,6 \%)$ e renda familiar de 1 salário mínimo (54,6\%). Durante as entrevistas, as participantes foram questionadas quanto às suas dúvidas ou dificuldades enfrentadas para a realização do cuidado ao recém-nascido, sendo suas respostas analisadas e categorizadas para então serem discutidas à luz da literatura correspondente.

A análise das falas obtidas demonstrou que a dificuldade mais prevalente foi a amamentação com $77,2 \%$, ou seja, 17 das 22 puérperas entrevistadas, seguida de engasgo e regurgitação com $68,2 \%$ (15), banho e higiene com $45,5 \%$ (10), choro com $27,3 \%$ (6), vacinas e suas reações adversas com $27,3 \%$ (6), soluços com $22,7 \%$ (5), infecções diarreicas com 22,7\% (5) e cólicas com apenas 13,6\% (3). No entanto, é importante considerar que cada participante relatou mais de uma categoria por variável. Optou-se em discutir as dificuldades que apresentaram uma prevalência maior que $25 \%$ conforme a categorização das falas analisadas, dentre elas: amamentação; engasgo e regurgitação; banho e higiene; choro; vacinas e suas reações adversas.

\section{Amamentação}

Os primeiros dias pós-parto e de convivência com o recém-nascido no domicílio são desafiadores para as primíparas, visto que a mulher encontra-se em uma situação nova, onde é necessário adaptar-se à rotina de cuidados consigo e com a criança, o que pode desencadear sentimentos conflitantes (PEREIRA MC, et al., 2012). 
No período da gestação, o acompanhamento de pré-natal é uma ótima oportunidade para o esclarecimento de informações a respeito do Aleitamento Materno (AM). Durante esse período as mulheres devem ser informadas sobre os principais aspectos da amamentação, qual o tempo adequado de Aleitamento Materno Exclusivo (AMEx) e quando inserir o complemento alimentar, além de dificuldades que elas possam enfrentar durante o processo de lactação (AZEVEDO DS, et al., 2010).

Órgãos internacionais como a Organização Mundial de Saúde (OMS) e Fundo das Nações Unidas para a Infância (UNICEF) afirmam que o AMEx deve ser ofertado até os seis meses de vida e, depois dessa idade, os lactentes devem receber alimentos complementares, não interrompendo com o leite materno até os dois anos ou mais. O AM fornece de modo insubstituível o alimento ideal para o crescimento e desenvolvimento saudável de lactentes, influenciando biológica e emocionalmente a saúde das mães e das crianças (GAíVA MAM e MEDEIROS LS, 2006).

Para Assis ELA, et al. (2014), as primíparas apresentam forte tendência a não oferecer o AMEx para os seus filhos. Dentre os fatores que podem colaborar com essa prática, estão: trabalhar fora do lar, problemas mamários, conhecimento insuficiente e a introdução precoce de alimentos.

Almeida IS, et al. (2010) acrescentam que o prosseguimento da amamentação exclusiva é definido pela experiência inicial da mãe com a prática do aleitamento materno. Se essa vivência for negativa para a puérpera, provavelmente ela terá dificuldades na continuação da amamentação exclusiva, principalmente em se tratando de primíparas. Ao analisar os dados, observamos relatos de algumas mulheres que iniciaram a amamentação e se queixaram de dificuldades, demonstrando falta de informação, conhecimento insuficiente e insegurança diante do novo desafio de nutrir:

\section{"Amamentar, ele não ta pegando de jeito nenhum" (Entrevistada 3). \\ "Sobre alimentação, qual alimento posso dar nos primeiros meses fora o leite materno" (Entrevistada 7).}

O pouco conhecimento e as dúvidas constantes sobre o significado e os benefícios do aleitamento materno exclusivo apresentado pelas mulheres deste estudo pode comprometer a amamentação de seus filhos, bem como a saúde destas mães, considerando que ambos estarão se privando das vantagens proporcionadas por essa prática.

Outra situação referida pelas mulheres entrevistadas, que vivencia o insucesso da amamentação, está relacionada à hipogalactia (diminuição da secreção láctea) ou "leite fraco", como podemos observar nos relatos que seguem:

"Ela chora muito, e é fome porque o leite não enche a barriga dela, é fraco demais, eu queria dar pelo menos o mingau" (Entrevistada 8).

"E com relação a amamentação, o meu peito o bico não é muito pra fora e sobre meu leite também que é aguado, acho que não vai matar a fome dele, se eu posso dar outra coisa" (Entrevistada 13).

"Sobre o leite materno que acho que não sustenta ele, é muito pouco" (Entrevistada 6).

A literatura aponta a percepção da diminuição da secreção láctea como um dos principais motivos para a interrupção do aleitamento materno. Um estudo desenvolvido na Espanha constatou que a sensação de hipogalactia foi o principal motivo referido pelas participantes para a interrupção do aleitamento materno (DÍAZ-GOMES NM, et al., 2016).

Entretanto, frequentemente, a percepção de leite fraco ou insuficiente para suprir às necessidades da criança é desenvolvida pela insegurança materna e permeada por aspectos culturais enraizados na sociedade. Essa insegurança, permite que as puérperas interpretem o choro do bebê e as mamadas frequentes - que fazem parte do comportamento normal dos lactentes - como sinais de fome, contribuindo para que essas mães questionem sua capacidade para nutrir plenamente o filho (BRASIL, 2014). 
Dessa forma, percebe-se que é fundamental que os profissionais de saúde estejam atentos às necessidades apresentadas, e que atuem escutando-as, oferecendo apoio, reforçando a importância da amamentação e promovendo intervenções para auxiliá-la nesse processo.

\section{Engasgo e Regurgitação}

A segunda dificuldade mais frequente verbalizada pelas entrevistadas foi o engasgo e a regurgitação, esta última foi definida por elas como "gofo" e "secreções do parto". Observou-se, nas falas que sucedem, preocupação, insegurança e falta de preparo para lidar com a situação do filho engasgado, havendo relatos de receio das mães primíparas em não saber reagir diante de tal situação:

"Com certeza é com relação a engasgo e se eu tiver só com ele, tenho medo de ficar agoniada e não saber o que fazer" (Entrevistada 1).

"Ta sendo tão bom cuidar dele, mas tenho medo de engasgar" (Entrevistada 14).

"Uma parte que tenho medo é do gofo que tenho medo quando ela gofar ela engasgar por isso que toda vez boto ela de ladinho no berço" (Entrevistada 2).

Com relação aos cuidados cotidianos durante as primeiras semanas de vida, constatamos que "Alexandrita" preocupava-se em colocar o filho para arrotar após as mamadas. Quando o mesmo não arrotava, ela o lateralizava, evitando uma possível broncoaspiração. O engasgo é considerado o resultado da permeação das vias aéreas por um corpo estranho que leva à apneia e tosse reflexa (BIGAL A, et al., 2007).

O estudo de Terra DLH e Okasaki ELFJ (2006) revela uma falta de orientação por parte das participantes sobre o que fazer em uma situação de engasgo, inclusive, houveram relatos de desespero como sair correndo com o bebê no colo chacoalhando sem saber o que fazer.

Quando a criança engasgar com leite, a mãe não deve conceder tapas nas suas costas, assoprar seu rosto ou chacoalhá-la, principalmente se ela estiver na posição vertical. O socorrista deve inclinar o corpo da criança com a cabeça voltada para baixo, e assim, dar alguns "tapinhas" nas costas, essa manobra ajudará no deslocamento do alimento que, pela ação da gravidade, voltará à boca da criança (TERRA DLH e OKASAKI ELFJ, 2006).

Duca AP (2004) define a regurgitação como o regresso involuntário de alimentos ou secreções para a boca. Penna et al. (2003) afirmam que as regurgitações pós-alimentares surgem entre o nascimento e os quatro meses de vida, podendo perdurar, na maioria dos casos, até um ano de idade. Sendo considerado mais frequente nos lactentes de baixo peso.

O número elevado de crianças com episódios frequentes de regurgitação nos dois primeiros trimestres de vida pode ser uma consequência do desmame precoce e da introdução da alimentação artificial, uma vez que o volume oferecido é imposto pelo cuidador, e não necessariamente controlado pela criança (ORENSTEIN S, 2001; COSTA et al., 2004).

\section{Banho e Higiene}

Entre as várias dúvidas e dificuldades enfrentadas pelas primíparas, a subcategoria banho e higiene representou quantidade significativa dos problemas frequentes relacionados ao recém-nascido, como observa-se nos relatos das entrevistadas frente a essa dificuldade:

"Nos primeiros dias foi pra dar banho, tive medo de pegar nela porque era muito molinha" (Entrevistada 11).

"Tenho dificuldade no banho porque tenho medo de entrar água no ouvido e queria saber quais são os cuidados no banho" (Entrevistada 9).

"No banho, porque eu não banho, só mamãe, tenho medo de quebrar os ossinhos" (Entrevistada 8).

"Se não fosse minha mãe aqui, até pra banhar eu tenho dificuldade" (Entrevistada 14). 
O banho do recém-nascido constitui um momento de grande insegurança para as mulheres. A execução dessa atividade por outros membros da família, quase sempre pela avó da criança, traz segurança para a puérpera (TOMELERI KR e MARCON SS, 2009). A busca por colaboração familiar é evidente, tendo em vista a percepção da importância de apoio para o esclarecimento de suas dúvidas, fazendo com que a puérpera se sinta mais segura e tranquila pela simples presença da pessoa como suporte que pode ser acionado caso precise (BERGAMASCHI SFF e PRAÇA NS, 2008).

Através das entrevistas, observou-se que as primíparas possuíam dúvidas elementares quanto à execução do banho do recém-nascido, tais como técnicas para segurá-lo, número de banhos diários, temperatura da água, cuidados com mucosas, entre outras. Portanto, evidenciou-se a necessidade da abordagem intensiva dessa atividade durante o pré-natal, em especial das primigestas. Outra discussão que pode ser incluída com relação ao banho e higiene é o cuidado com o coto umbilical. Na presente pesquisa as primíparas proferiram as seguintes falas:

"Tenho medo de banhar e trocar ele por causa do umbigo, minha mãe que ta banhando ele, ela banha e passa álcool a 70\% direitinho" (Entrevistada 1).

"Sobre o curativo do umbigo, se pode deixar aberto ou não e quanto tempo demora pra cair" (Entrevistada 6).

As dificuldades apresentadas com esse cuidado são muito evidentes na primeira semana de vida da criança, pois ele é visto como sendo "algo perigoso", "que pode sangrar". Após a experiência do primeiro filho, elas sentem-se mais seguras quanto ao manuseio e a queda do coto umbilical. Para as mães, o coto umbilical é envolvido por mistério, desconhecimento e ambiguidade, uma vez que ele tanto "alimenta a criança", como "pode levar a doença" (TOMELERI KR e MARCON SS, 2009).

Os cuidados com o coto umbilical estão cercados por crenças e mitos, práticas sem fundamentações científicas ainda são difundidas como enfaixar o coto, colocar moeda, realizar simpatias utilizando diferentes ingredientes, tais como banha de galinha, azeite e folha de fumo. Tais práticas podem desencadear infecções graves podendo culminar na morte do recém-nascido (RIBEIRO MB e BRANDÃO MNM, 2011; LINHARES $E F$, 2018). De acordo com a Organização Pan-Americana da Saúde (OPAS), o coto umbilical deve permanecer higienizado e seco, objetivando uma rápida cicatrização e redução de complicações. Recomenda-se higienizar pelo menos duas a três vezes ao dia, utilizando álcool a $70 \%$ ou clorexidina alcoólica 0,5\% (OPAS, 2016).

\section{Choro}

Algumas puérperas $(27,3 \%)$ mencionaram que possuíam dificuldade de manejo com o choro dos recémnascidos. Como pode ser observado a seguir:

"Sobre o choro, ela chora muito, eu acho que é fome ou cólica" (Entrevistada 8).

"Minha dificuldade mesmo é descobrir o que ele ta sentindo, porque ele não fala, só através do choro e as vezes a gente não consegue" (Entrevistada 12).

"Com o choro, ela chora e eu fico agoniada pensando que é alguma coisa e boto no peito, não tenho paciência” (Entrevistada 4).

"É as crises de choro do bebê, ai eu fico desesperada, sem saber o que fazer" (Entrevistada 5).

Para Folle E e Geib LTC (2004) um dos maiores desafios enfrentados pela família, no início da convivência com o recém-nascido, é interpretar o comportamento do bebê, especialmente quando esse se expressa através do choro. A sensação de incapacidade para acalmar a criança, nesses momentos, é apontada pelas mulheres como uma dificuldade no exercício do cuidado materno. Nas primeiras semanas é comum ter dificuldade para identificar se o choro do bebê é referente a dor, sono, fome, cólica, eliminações vesicais ou intestinais, sustos, desconfortos, entre outras possibilidades. A dificuldade em decifrar o significado do choro do bebê, causa sentimentos de preocupação, impotência e frustração, especialmente nas primigestas, neste período de adaptação (STRAPASSON MR e NEDEL MNB, 2010). 
Gradativamente os pais vão aprendendo a distinguir as melodias dos tipos de choro e os tipos de linguagem corporal do bebê. Para tanto, é necessário paciência, sensibilidade e atenção para compreender as necessidades do recém-nascido. Tal processo fica mais fácil com o tempo, e a partir do segundo filho, pois a prática do primeiro auxilia na assimilação (TOMELERI KR e MARCON SS, 2009).

\title{
Vacinas e suas reações adversas
}

Outras puérperas $(27,3 \%)$ mencionaram que possuíam dúvidas quanto às vacinas e suas reações adversas, como pode ser observado nas falas a seguir:

\author{
"Vacinas também que não sei ainda" (Entrevistada 9). \\ "Vai ser difícil ver ela tomando um monte de vacina, uma atrás da outra, ela vai ficar \\ enjoadinha porque esse tanto de vacina deve dar gripe, febre, moleza" (Entrevistada \\ 10).
}

A vacinação, especialmente, referente a lactantes e crianças na primeira infância, representa uma significativa atitude de prevenção de doenças infectocontagiosas. Há pouco tempo, tais doenças comuns na infância levaram ao óbito e a sequelas um grande contingente de crianças. Entretanto, sabe-se que milhões de crianças ainda continuam morrendo anualmente em todo o mundo, devido a doenças que poderiam ser evitadas através da imunização (SOUSA CJ, et al., 2012).

No Brasil, o Ministério da Saúde desenvolve tais atividades e promove, de forma regular, campanhas com o intuito de controlar e erradicar doenças a partir da vacinação maciça de crianças. Apesar disso, muitas destas deixam de ser vacinadas pelos mais diversos fatores, como crenças, superstições, mitos e credos religiosos (SILVEIRA ASA, et al., 2007).

Apesar da confiabilidade das vacinas, estas podem provocar alguns efeitos adversos, podendo ser mais leves como febre, dor e edema local, ou mais grave como convulsões febris, episódio hipotônicohiporresponsivo, anafilaxia etc. Porém, o risco de ocorrer uma complicação grave é muito baixo (BRASIL, 2014).

Principalmente para as primíparas, o medo dos efeitos adversos e a grande oferta de vacinas são vistos como causadores de dor e angústia para com seus filhos. Porém, a prática de multivacinas, apesar de temerosa, é indicada, pois representa facilidade para os indivíduos, em decorrência de um menor contato com os serviços de saúde e serem menos onerosos. Além disso, a administração simultânea não compromete a capacidade imunogênica dos imunobiológicos e não causam aumento na frequência ou gravidade das reações adversas (SOUSA CJ, et al., 2012).

Dessa forma, a população deve receber informações adequadas acerca dos possíveis efeitos adversos da vacinação, visando ao não comprometimento da confiança dos imunobiológicos pelos usuários e, consequentemente, uma baixa adesão vacinal, podendo acarretar em maiores complicações para a saúde coletiva (SOUSA CJ, et al., 2012).

Os profissionais de saúde, tanto ainda na maternidade quanto na ESF, são os responsáveis por prestar orientações sobre a prevenção das doenças infectocontagiosas, benefícios das vacinas e seus efeitos adversos. Além disso, profissionais da ESF, durante visitas domiciliares ou consultas de rotina, devem verificar as vacinas já aplicadas no cartão de vacinação na criança no decorrer do desenvolvimento da mesma.

Nesse estudo, outras dúvidas e dificuldades pouco apresentadas pelas puérperas primíparas transitaram em torno de: sono da criança (9\%), alergias $(9 \%)$, quedas $(4,5 \%)$, medicações $(4,5 \%)$, agasalhamento $(4,5 \%)$, assaduras $(4,5 \%)$ e sobre o modo como segurá-lo no colo corretamente $(4,5 \%)$. Diante deste cenário, os profissionais da área de saúde envolvidos em sua assistência, sobretudo os enfermeiros, devem acolher a mulher, ouvi-la e realizar ações educativas no decorrer de todas as fases do ciclo gravídico-puerperal, respeitando seu conhecimento e individualidade.

Estes deverão estar aptos a prestar uma assistência de qualidade, orientá-las sobre o autocuidado e os cuidados relacionados ao recém-nascido e esclarecer dúvidas que poderão surgir dentro da nova realidade que irão vivenciar. 


\section{CONCLUSÃO}

O estudo possibilitou compreender que, embora as puérperas tenham sido orientadas quanto aos cuidados com o recém-nascido, todas apresentaram dúvidas e dificuldades para realizarem tal prática por diversos motivos, sendo a primiparidade o principal deles e revelando aos profissionais de saúde as necessidades no enfrentamento da maternidade. Concluímos, portanto, que a assistência de enfermagem deve direcionar suas ações com base na necessidade individual de cada binômio mãe-filho. Nesse contexto, faz-se necessário o desenvolvimento de novos estudos, programas e ações de educação em saúde com atividades de capacitação da gestante e seu parceiro com o objetivo de instrumentalizá-los para os cuidados gerais com o recém-nascido, tornando-os sujeitos ativos e não expectadores das ações dos profissionais de enfermagem.

\section{REFERÊNCIAS}

1. ALMEIDA IS, et al. Amamentação para mães primíparas: perspectivas e intencionalidades do enfermeiro ao orientar. Cogitare Enfermagem, 2010; 15(1): 19-25.

2. ASSIS ELA, et al. Dificuldades enfrentadas por puérperas primíparas em relação ao aleitamento materno exclusivo. Gestão e Saúde, 2014; 5(3): 808-819.

3. AZEVEDO DN, et al. Conhecimento de primíparas sobre os benefícios do aleitamento materno. Revista da Rede de Enfermagem do Nordeste, 2010; 11(2): 53-62.

4. BARDIN L. Análise de conteúdo. Tradução Luís Antero Reto, Augusto Pinheiro. São Paulo: Edições 70, 2011.

5. BERGAMASCHI SFF, PRAÇA NS. Vivência da puérpera-adolescente no cuidado do recém-nascido, no domicílio. Revista da Escola de Enfermagem da USP, 2008; 42(3): 454-460.

6. BIGAL A, et al. Disfagia do idoso: estudo videofluoroscópico de idosos com e sem doença de Parkinson. Rev. Distúrbios da Comunicação, 2007; 19(2): 213-223.

7. BOSCO SMD, CONDE SF. Nutrição e Saúde. Lajeado: Editora UNIVATES, 2013. Disponível em: <http://web2db2.univates.br/editora-univates/media/publicacoes/53/pdf_53.pdf\#page=83>. Acesso em: 11 jun. 2016

8. BRASIL. Ministério da Saúde. Secretaria de Atenção à Saúde. Departamento de Ações Programáticas Estratégicas. Atenção à saúde do recém-nascido: guia para os profissionais de saúde / Ministério da Saúde, Secretaria de Atenção à Saúde, Departamento de Ações Programáticas Estratégicas. - 2. ed. atual. - Brasília Ministério da Saúde, 2014.

9. BRASIL. Ministério da Saúde. Secretaria de Atenção à Saúde. Departamento de Ações Programáticas e Estratégicas. Atenção à saúde do recém-nascido: guia para os profissionais de saúde. Brasília: Ministério da Saúde, 2011. 167p.

10. BRASIL. Ministério da Saúde. Secretaria de Atenção à Saúde. Departamento de Atenção Básica. Atenção ao prénatal de baixo risco. Departamento de Atenção Básica. - Brasília: Editora do Ministério da Saúde, 2012. 318 p.

11. CARDOSO ACA, VIVIAN AG. Maternidade e suas vicissitudes: a importância do apoio social no desenvolvimento da díade mãe-bebê. Diaphora, 2018; 17(1): 43.

12. COSTA PF, BRITO RS. Orientações ofertadas às puérperas no alojamento conjunto: revisão integrativa da literatura. Espaço para Saúde, 2016; 17(2): 237-245.

13. DÍAZ-GOMEZ NM, et al. Motivaciones y barreras percibidas por las mujeres españolas en relación a la lactancia materna. Revista española de salud pública, 2016; 90.

14. DUCA AP. Deglutição em crianças com refluxo gastroesofágico: avaliação clínica fonoaudiológica e análise videofluoroscópica. 2004. 133 f. Dissertação (Investigação Biomédica aplicada a Clínica Médica). Faculdade de Medicina de Ribeirão Preto, Universidade de São Paulo (USP), Ribeirão Preto, 2004.

15. FERNANDES ANML, et al. A educação da saúde da mulher-mãe e da criança na revista eu sei tudo nas primeiras décadas do século XX. Rio de Janeiro: Eu Sei Tudo, 2014.

16. FOLLE E, GEIB LTC. Representações sociais das primíparas adolescentes sobre o cuidado materno ao recémnascido. Revista Latino-Americana de Enfermagem, 2004; 12(2): 183-190.

17. GAÍVA MAM, MEDEIROS LS. Lactação insuficiente: uma proposta de atuação do enfermeiro. Ciência, cuidado e Saúde, 2006; 5(2): 255-262.

18. LINHARES EF. Tenho guardado os "imbigo" de todos os meus netos: memória de avós no cuidado com o coto umbilical. Vitória da Conquista, 2018.

19. MONTE CMG, GIUGLIANI ERJ. Recomendações para alimentação complementar da criança em aleitamento materno. Jornal de Pediatria, 2004; 80(5): s131-s141.

20. MOREIRA MC, et al. As medidas utilizadas pelas mães de recém-nascidos para amenizar a cólica de seus filhos. São Paulo: Rev Esc Enferm, 2004.

21. OPAS. Organização Pan-Americana da Saúde. Centro Latino-Americano de Perinatologia, Saúde da Mulher e Reprodutiva. Prevenção de infecções relacionadas à assistência à saúde em neonatologia. Montevidéu: CLAP/SMROPS/ OMS, 2016.

22. ORENSTEIN S. Regurgitation \& GERD. Journal of pediatric gastroenterology and nutrition, 2001; 32: S16-S18.

23. PENNAFJ, et al. Comparação entre uma fórmula infantil pré-espessada e fórmula de espessamento caseiro no tratamento do refluxo gastroesofágico. Jornal de Pediatria, 2003; 79(1): 49-54.

24. PEREIRA MC, et al. Sentimentos da puérpera primípara nos cuidados com o recém-nascido. Cogitare Enfermagem, 2012; $17: 3$. 
25. RAPOPORT A, PICCININI CA. Maternidade e situações estressantes no primeiro ano de vida do bebê. Psico-Usf, 2011; 16(2): 215-225.

26. RIBEIRO MB, BRANDÃO MNM. A produção científica da Enfermagem sobre coto umbilical. Revista Interdisciplinar Novafapi, 2011; 4(3): 54-59.

27. SILVEIRA ASA, et al. Controle de vacinação de crianças matriculadas em escolas municipais da cidade de São Paulo. Revista da Escola de Enfermagem da USP, 2007; 41(2): 299-305.

28. SOUZAZNR, et al. Maternidade: percepções de gestantes primíparas usuárias do Serviço Básico de Saúde. J Health Sci Inst., 2011; 29(4): 272-275.

29. SOUSA CJ, et al. Compreensão dos pais acerca da importância da vacinação infantil. Revista Enfermagem Contemporânea, 2012; $1: 1$.

30. STRAPASSON MR, NEDEL MNB. Puerperio inmediato: desvendando el significado de la maternidad. Revista Gaúcha de Enfermagem, 2010; 31(3): 521-528.

31. TERRA DLH, OKASAKI ELFJ. Compreensão de puérperas primíparas sobre os cuidados domiciliares com o recémnascido. Rev. Enferm. UNISA, 2006; 7: 15-20.

32. TOMELERI KR, MARCON SS. La madre adolescente cuidando al niño en la primer semana de vida. Revista Brasileira de Enfermagem, 2009; 62(3): 355-361.

33. WESSEL MA, et al. Paroxysmal fussing in infancy, sometimes called "colic". Pediatrics, 1954; 14: 421-34. 